\title{
Profit vs ethics
}

Shaun Sellars continues this exciting and essential series on ethical dilemmas in dentistry which appears in every second issue of the $B D J$

'Put patients' interests first.' It sounds so simple, and yet it's something that we often struggle with day to day.

Dentistry is different to the many forms of healthcare in the UK. At the heart of general and specialist practice are thousands of small businessmen and women, be they sole traders or contracted to larger companies. Providing healthcare in an increasingly commercial world leads us to conduct a precarious balancing act of making income for our practice and being an ethical practitioner.

We're primed to think of our duties to our patients, but when we start to consider the business of dentistry, we have many more obligations to consider. One of these is to the business that we run and the people who work for and with us. We all have to make a living, and generally speaking, as dentists we do better than most. Despite this, the pressure to increase profit is ever present.

The idea of a 'healthcare business' raises a number of questions, especially for those of us used to the majority of healthcare being provided free at the point of delivery. Should we consider healthcare provision as a business in the first place? How much of an emphasis do we place on the business over healthcare? Too much weight on the business side and our honesty and reputation can suffer. The drive for profit can lead us away from the true goal of healthcare - caring for health. However, if we neglect to think of the bottom line, we risk not being able to provide healthcare at all.

Dentistry has, it could be claimed, become a product. Dentists are considered salesmen, to the point where we have courses on how to improve your 'ethical sales' techniques. What's really on sale is the dentist. Patients buy into us, and to a certain extent we are the product and what we are selling is our skills. This trust has the potential to lead to corruption, especially if the financial pressures of business weigh heavy. These pressures exist to a lesser extent in the salaried dental services, but they're not completely absent, especially as many services are contracted to

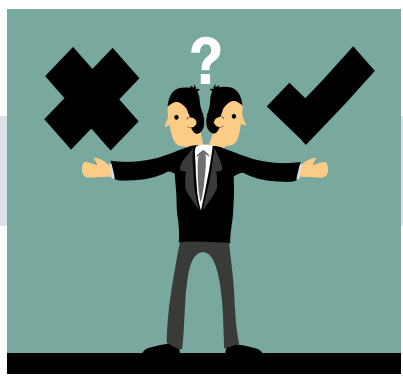

private companies. Whether income is measured in UDAs delivered or in pounds and pence, getting this balance right is paramount.

Part of being a professional is being able to balance these demands, but how do we keep ourselves in check? How do we ensure that our drive for profit doesn't affect our need to be ethical?

We all know that prevention is better than cure. If our business has a set of rules to guide our decision making in the first place, then going off course is more difficult. Ethical guidelines and checklists make planning that course easier. It also makes sure that everyone in the business is on board with the company ethos. When this happens, not only do we stay on the right side of ethical, our business can run efficiently, with direction and guidance to make it profitable.

\section{View from my window}

\section{In 2014-15, we published a series of views} from readers' surgery windows in $B D J$ Upfront. After a call-out on social media, we are restarting the series in 2019.

Rachel Jackson, a dental therapist, has sent this view from her surgery window at
Tain Dental Care in the burgh of Tain in the Highlands of Scotland (pictured).

If you would like to send a photograph of the view from your window for consideration for publication in BDJ Upfront, please email the News Editor, Kate Quinlan, k.quinlan@nature.com. Please include your name, job title, workplace and a brief description of the view from your window.

If there are people in your photograph, please confirm that they have given their permission for the photograph to be published in the $B D J$.

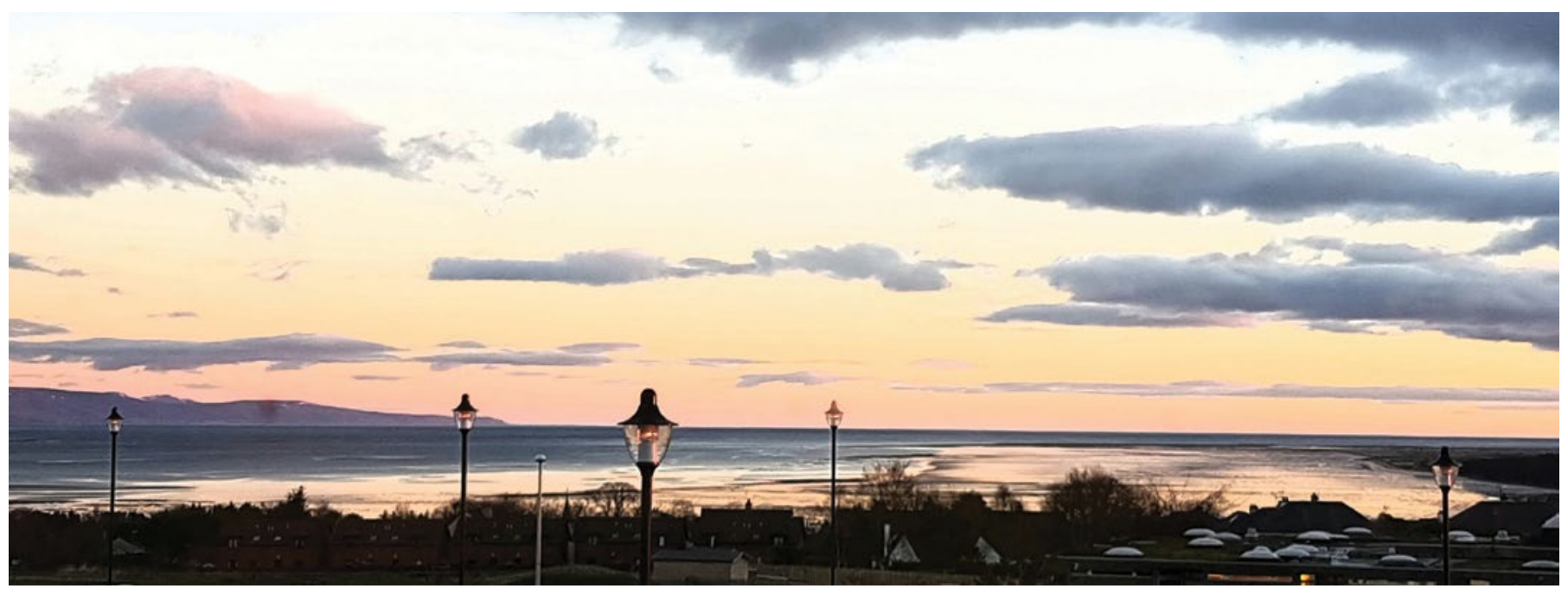

